\title{
GRÉCKOKATOLÍCKA CIRKEV NA PODKARPATSKEJ RUSI A STRET KULTÚR V ROKU $1945^{1}$
}

\author{
Greek Catholic Church in Carpathian Ruthenia \\ and Clash of Cultures in 1945
}

\author{
Peter Borza
}

DOI: 10.17846/CL.2019.12.2.127-134

\begin{abstract}
BORZA, Peter. Greek Catholic Church in Carpathian Ruthenia and Clash of Cultures in 1945. The Greek Catholic Church in Carpathian Ruthenia held a prominent place in society and 1945 was a dramatic twist in the life of Greek Catholics in Carpathian Ruthenia. The connection to the Soviet Union was not only accompanied by the loss of freedom in the totalitarian regime, but also by the degradation of cultural values that have been built up in society for centuries. The Greek Catholic Church, as one of the most influential bearers the saint Cyril and Methodius cultural heritage of the Subcarpathian people, soon became a real cataclysm after the Soviet power came into existence, and officially ceased to exist, but in reality it continued to operate in real life until the resurgence after the fall of communism. The presented paper offers an outline of the issues of the activities of the Greek Catholic Church and its attitudes in the environment of the Czechoslovak Republic, during the Second World War and finally its fate in the process of affiliation of Carpathian Ruthenia to the Soviet Union.
\end{abstract}

Keywords: Greek Catholic Church, Carpathian Ruthenia, Czecho-Slovakia, Soviet Union, communism, heritage of Saints Cyril and Methodius

\begin{abstract}
Abstrakt: BORZA, Peter. Gréckokatolícka cirkev na Podkarpatskej Rusi a stret kultúr v roku 1945. Gréckokatolícka cirkev na Podkarpatskej Rusi zastávala významné miesto v spoločnosti a rok 1945 bol dramatickým zvratom v živote gréckokatolíkov na Podkarpatskej Rusi. Pripojenie k Sovietskemu zväzu nebolo sprevádzané len stratou slobody v totalitnom režime, ale aj degradáciou kultúrnych hodnôt, ktoré boli v spoločnosti po stáročia budované. Gréckokatolícka cirkev ako jedna z najvplyvnejších nositeliek cyrilo-metodského kultúrneho dedičstva podkarpatoruského ludu prešla čoskoro po nástupe sovietskej moci skutočnou kataklizmou a oficiálne prestala existovat', ale v ilegalite reálne pôsobila dảej až do obnovenia po páde komunizmu. Predložený príspevok ponúka náčrt problematiky činnosti gréckokatolíckej cirkvi a jej postojov v prostredí Československej republiky počas druhej svetovej vojny a napokon jej osudy v procese pričlenenia Podkarpatskej Rusi k Sovietskemu zväzu.
\end{abstract}

Klúčové slová: gréckokatolícka cirkev, Podkarpatská Rus, Československo, Sovietsky zväz, komunizmus, cyrilo-metodské dedičstvo

Príspevok bol spracovaný v rámci riešenia grantového projektu VEGA č. 1/0184/17 Gréckokatolícka cirkev na okupovaných územiach Československa v rokoch 1938 - 1945. 
Gréckokatolícka cirkev v dejinách Podkarpatskej Rusi zohrávala v jej zlomových okamihoch vždy dôležitú úlohu. Rok 1945 bol dramatickým zvratom v živote obyvatelov Podkarpatskej Rusi. Pripojenie k Sovietskemu zväzu nebolo sprevádzané len stratou slobody v totalitnom režime, ale aj degradáciou kultúrnych hodnôt, ktoré boli v spoločnosti po stáročia budované. Gréckokatolícka cirkev, ktorá bola jednou z najvplyvnejších nositeliek cyrilo-metodského kultúrneho dedičstva podkarpatoruského obyvatel'stva prešla čoskoro po nástupe sovietskej moci skutočnou kataklizmou a de iure zanikla, ale v ilegalite de facto pôsobila dalej až do obnovenia v roku 1989. Predložená štúdia ponúka náčrt problematiky činnosti gréckokatolíckej cirkvi a jej postojov v prostredí Československej republiky, počas druhej svetovej vojny a napokon jej osudy v procese pričlenenia Podkarpatskej Rusi k Sovietskemu zväzu. Zámerne sa pritom vyhýba otázkam postavenia jednotlivých národností na jej území, a len okrajovo zachytáva aj túto oblaste činnosti gréckokatolíckych predstavitel'ov, kedže danej téme sa už podrobne venovalo viacero autorov, ako napríklad Paul Robert Magocsi, ktorý uvádza až 2326 publikácií na túto tému (Magocsi1994, 246-285).

Príchod Červenej armády na územie Podkarpatskej Rusi v závere druhej svetovej vojny znamenal nielen koniec vojnového strádania, ale priniesol aj obavy z dalšieho vývoja. Nádej v deklarované znovuobnovenie Československa narušilo jednanie Sovietskeho zväzu v prospech pripojenia k Ukrajinskej sovietskej socialistickej republike (Švorc 1996, 104-109).

Gréckokatolícka cirkev sa tak ocitla pred najtragickejším obdobím vo svojich dejinách a výzvou čelit totalitnému režimu, ktorý svoje záujmy presadzoval tým najbrutálnejším spôsobom, o čom sa duchovenstvo a veriaci čoskoro presvedčili na vlastnej koži. Paradoxne v roku 1945 stáli gréckokatolíci na prahu osláv 300. výročia uzatvorenia Užhorodskej únie z roku 1646 a práve spojenie s katolíckou cirkvou bolo podrobené neobvyklej skúške. Príslušnost' k rímskemu pápežovi je jedným z troch prvkov cyrilo-metodského kultúrneho dedičstva $v$ gréckokatolíckej cirkvi a zároveň ju odlišuje od pravoslávnej cirkvi. Ďalšími sú spoločné elementy ako byzantský obrad a liturgický jazyk. Výnimočnost' gréckokatolíckej cirkvi umocňuje to, že je nositelkou modelu krestanstva od sv. Cyrila a Metoda, ktorý bol vždy spätý s pápežom a vyznačoval sa uznaním jeho autority. V priebehu dejín sa gréckokatolíci rôznou intenzitou hlásili k odkazu sv. Cyrila a Metoda, pričom väčší dôraz sa na prínos byzantskej misie dával od vzniku Československej republiky. Najvýraznejšiu stopu zaznamenali unionistické kongresy konané na Velehrade v rokoch 1907 - 1936 a 1946 - 1947 hlásiace sa k odkazu sv. Cyrila a Metoda. Ich účastníkmi boli aj gréckokatolícki biskupi, ktorí svojou aktívnou prítomnostou na Velehrade zdôrazňovali cirkevnú jednotu. Mukačevský biskup Peter Gebej počas jedného z nich v roku 1924 prijal biskupskú vysviacku, a tým sa aj prihlásil k cyrilo-metodskému odkazu i spoločnej štátnosti. V podobnom duchu vyzneli aj oslavy 1100. jubilea posvätenia prvého krestanského kostola v Nitre, oslavy dostali názov podla kniežata Pribinu - Pribinove slávnosti. Pri príležitosti jubilea bola v Trnave vydaná reprezentačná publikácia Katolícke Slovensko 833 1933, v ktorej boli uverejnené aj texty gréckokatolíckych biskupov Pavla Petra Gojdiča OSBM z Prešova a Alexandra Stojku z Užhorodu (Borza 2013, 169-170).

Gréckokatolícka cirkev v Československu bola organizovaná v dvoch eparchiách. Prešovskú eparchiu postupne tvorili farnosti v Čechách, na Morave a Slovensku. Mukačevská eparchia zahŕňala predovšetkým farnosti na Podkarpatskej Rusi a čast’ aj na Slovensku. Sídlom Mukačevskej eparchie bolo mesto Užhorod, kde mukačevskí biskupi sídlili už od 18. storočia (Katolícke Slovensko, 1933, 148-149) .

Bezprostredne po prvej svetovej vojne prežívala Mukačevská eparchia rôzne tažkosti. Okrem už spomínaného odcudzenia sa veriacim, pretrvávala medzi duchovenstvom a inteligenciou nostalgia za pomermi v monarchii a $\mathrm{z}$ toho plynúce tažkosti včlenit’ sa do nového politického a sociálneho systému. Skutočnost', že mukačevský biskup Anton Papp sa zriekol biskupstva a väčšina duchovných odmietla vyjadrił svoju lojalitu novému Československému štátu, mala 
za následok nezáujem štátnych orgánov o právnu ochranu gréckokatolíckej cirkvi. Túto situáciu využilo pravoslávne hnutie, ktoré bolo podporované niektorými protikalolíckymi kruhmi novej vlády. Propaganda pravoslávnych vyslancov z Haliče a Bukoviny, sociálna tieseň chudobného ludu Podkarpatskej Rusi, emigrácia pravoslávnych kňazov a reholníkov po októbrovej revolúcii v roku 1917 spôsobili na území Mukačevskej eparchie rozšírenie pravoslávia. Prechod k pravosláviu bol často sprevádzaný násilnostami, fyzickými útokmi na kňazov a násilným zaberaním chrámov. Gréckokatolícku cirkev do roku 1930 opustilo viac ako 100-tisíc veriacich (Vasil' 2000, 125). Sčítanie obyvatel'stva uskutočnené v tom istom roku napriek zložitej situácii potvrdilo majoritné postavenie gréckokatolíckej cirkvi na Podkarpatskej Rusi. Z celkového počtu 725357 obyvatelov sa za gréckokatolíkov prihlásilo 359166 veriacich. Z dalších vierovyznaní boli zastúpení veriaci pravoslávnej cirkvi 112 034, židia 102 542, evanjelici reformovaní 70 833, rímskokatolícki veriaci 69 262, bez vyznania 4953 a tiež neznámi 6567 (Statistický lexikón 1937, 10).

Od 17. storočia totiž gréckokatolícka cirkev na území Podkarpatskej Rusi nadobudla významné postavenie a vplyv, ktorý sa v 20. storočí prejavoval v oblasti štátnej správy a vzdelávania (Pop 2008; Fenich 2015, 102-125). Vzdelávací systém Mukačevskej eparchie tvoril komplex vzdelávacích a výchovných inštitúcii, ktoré sídlili nielen v Užhorode, ale aj Chuste a jednotlivých farnostiach. Gréckokatolícke cirkevné školy prepracovaným vzdelávaním a výchovou smerovali $\mathrm{k}$ výchove gréckokatolíckej inteligencie. K tomu slúžila siet škôl vo farnostiach, ponúkajúca základné vzdelanie a v Užhorode bola možnost’ pokračovat v dalšom štúdiu v inštitúciách, akými boli Teologické lýceum, Kňazský seminár, dve pedagogické školy. Potrebné zázemie študentom poskytovali dievčenské a chlapčenské internáty v Užhorode a Chuste. Siet škôl bola systematicky budovaná od 18. storočia a jej cielom bolo pozdvihnút vzdelanostnú a kultúrnu úroveň gréckokatolíkov v Mukačevskej eparchii (Schematizmus 1939, 31-36).

Okrem vzdelávacích inštitúcii pôsobili rôzne náboženské a kultúrne spolky formujúce mládež a veriacich gréckokatolíckej cirkvi. Medzi nich patrili najmä spolky Duchnovič, Prosvita a Školská pomoc. Vo farnostiach svoju činnost̉ vykonávali náboženské organizácie ako Apoštolská modlitba a Mariánska družina. Súčastou aktivít bolo aj vydávanie početných titulov tlače, ktorá vystupovala aj kriticky voči československým orgánom a ich sociálno-ekonomickým alebo politickým aktivitám na Podkarpatskej Rusi. K formovaniu gréckokatolíkov prispieval aj Rád sv. Bazila Vel'kého a jeho najvýznamnejší kláštor na Černečej hore v Mukačeve, ktorému v roku 1926 pápež Pius XI. daroval vzácnu ikonu Matky Božej z 15. storočia. Daná udalost' viedla k založeniu tradície mariánskych pútí v Mukačeve (Hranchak 1995, 442-443).

Uprázdnené miesto biskupa Mukačevskej eparchie po konsolidácii pomerov v gréckokatolíckej cirkvi obsadil biskup Peter Gebej, ktorý ho viedol v rokoch 1924 - 1931. S menom tohto biskupa, ordinovaného na Velehrade 3. augusta 1924, sa spája obnovenie cirkevného života v Mukačevskej eparchii. Biskup P. Gebej pochopil dôležitosṫ včlenenia cirkvi do novej politickej skutočnosti. Nadviazal kontakty s vládou, čím dosiahol aj isté prevzatie záväzkov štátu v otázke materiálneho zabezpečenia duchovenstva, čo riešil kongruový zákon (Zákon kongruový č. 122/1926 Sb. z.) z 26. júla 1926. To dovolilo vylepšit ekonomickú situáciu kléru a uspokojit’ veriacich, ktorí sa nachádzali často v konfliktoch so svojimi farármi, ktoré sa vyskytli v živote práve kvôli zastaranému polofeudálnemu systému splácania cirkevných poplatkov. Iný zákon z 23. apríla 1925 o vztahoch medzi rôznymi náboženstvami (Zákon č. 96/1925 Sb. z.) dovolil pribrzdit násilie, ktoré sprevádzalo prestup na pravoslávie. Odvolávajúc sa na tento zákon dosiahli gréckokatolíci vrátenie mnohých chrámov a iných cirkevných budov, ktoré im nezákonne zabrali pravoslávni (Pekar 2000, 119). Známa je snaha biskupa P. Gebeja aj o oživenie náboženského života, oživenie na poli verejného vzdelania, v oblasti apologetickej a misijnej tlače a pri podpore ludových misií. Biskup P. Gebej ustanovil aj takzvanú Centrálnu kanceláriu na obranu viery, ktorej úlohou bolo usmerňovat zákonodarnú prácu na obranu práv gréckokatolíckej cirkvi. Bohužial, 
čast duchovenstva s prevažne promad’arským cítením sa bránila niektorým rozhodnutiam biskupa na kultúrnom a národnom poli. Tieto tažkosti zašli až tak daleko, že prinútili biskupa žiadat’ o demisiu, ktorú však Svätá stolica bez meškania odmietla. Dňa 25. apríla 1931 biskup P. Gebej vo svojom príhovore ku kňazom oznámil navrátenie posledného chrámu, ktorý násilne zabrali pravoslávni. Nasledujúci deň 26. apríla 1931 zomrel (Vasil 2000, 128-130).

Po výbere vhodného kandidáta Svätá stolica menovala v roku 1932 Alexandra Stojku na post biskupa Mukačevskej eparchie. Následne ju viedol v rokoch 1932 - 1943. Biskupom sa stal v období ekonomickej depresie a vyznačoval sa hlbokou náklonnostou k sociálnej otázke. Svojimi pastoračnými a politickými opatreniami, ako aj osobným príkladom vyzýval všetkých na pomoc najchudobnejším. V rozličných prípadoch sa stal aj sprostredkovatelom medzi sociálne slabými vrstvami a vládou, štrajkujúcimi robotníkmi a zamestnávatelmi, čo vyvolalo osobitnú sympatiu medzi veriacimi. Na úrovni kultúrnej a národnostnej orientácie v období jeho spravovania biskupstva sa stretávame s rôznymi prúdmi, jedným rusofilským, d’alším ukrajinským a promadarským. Ten posledný bol predstavovaný často ako výraz hladania osobitnej identity karpato-ruského národa (Vasil 2000, 128-130). Prevratné politické zmeny na jeseň 1938 a na jar 1939 narušili aj cirkevný život. Znovuobsadenie územia Mukačevskej eparchie Mad’arskom prijal biskup A. Stojka v začiatkoch s pokojom a lojálnostou. Túžba po zlepšení ekonomickej situácie ho načas primkla ku niektorým promadarsky orientovaným politikom, ktorí pracovali na znovupripojení Podkarpatskej Rusi k Mad’arsku. V roku 1939 po rozpade Československa a po anexii Podkarpatskej Rusi bol biskup A. Stojka mad’arskými úradmi najprv favorizovaný, ale onedlho nato sa ich postoj voči nemu radikálne zmenil. Kedže sa dožadoval dodržiavania národnostných práv pre Rusínov, stratil priazeň mad’arských vládnych kruhov, ktoré začali proti nemu silnú politickú kampaň s ciel’om odstránit ho z mukačevského biskupského stolca. Konečným výsledkom bolo to, že biskup A. Stojka zanechal politické otázky a sústredil svoju pozornost̉ na apoštolát a na pastoračnú a sociálnu činnost̉ pre dobro svojich veriacich (Pop 2008, 235).

Špecifikom vojnového obdobia bola pomoc rasovo prenasledovaným Židom, ktorí unikali pred perzekúciami z okupovaného Pol'ska do Mad’arska, ktorého súčastou bola aj Podkarpatská Rus. Poskytnutie nezištnej pomoci možno pozorovat na príklade kňaza Jozefa Borovského a jeho manželky Evy, ktorí pochádzali zo slovenskej časti Mukačevskej eparchie. Obaja boli za svoju nezištnú pomoc Židom ocenení štátom Izrael 16. marca 2009 udelením vyznamenania in memoriam Spravodlivý medzi národmi, ktoré bolo odovzdané príbuzným 27. januára 2010 v Bratislave. Na Slovensku prebiehala pomoc prenasledovaným Židom zo strany gréckokatolíckej cirkvi už od roku 1939, kedže ich postavenie v spoločnosti bolo ovela horšie ako v Madarsku (Borza 2014, 112-128).

Jozef Borovský sa narodil 23. októbra 1906 vo Vel'kom Ruskove (okr. Trebišov). Študoval v Košiciach a v Užhorode. V roku 1934 uzavrel sviatost̉ manželstva s Evou Dudinskou, s ktorou mali šest' detí. Prvé z nich však skoro po narodení zomrelo. $\mathrm{V}$ tom istom roku mu mukačevský biskup Alexander Stojka udelil v Užhorode sviatost' kňazstva a vymenoval ho za administrátora farnosti Latorka na Podkarpatskej Rusi. Vo farnosti pôsobil desat rokov a od roku 1945 až do roku 1950 v Stankoviach. Počas komunizmu bol väznený a poslaný do vyhnanstva v Čechách. Koncom 50. rokov sa mohol vrátit do svojho rodiska na Slovensko, kde pracoval v jednotnom rolníckom družstve. Zdravotné dôvody mu po roku 1968 nedovolili vrátit sa do pastorácie. Zomrel 17. júna 1973 (Babjak 2009, 337-339).

Počas druhej svetovej vojny riskovali s manželkou svoje životy, aby zachránili pred istou smrtou v koncentračnom tábore rodinu Dávida Gesslera. A okrem neho aj Eleka Gesslera, Lily Gesslerovú a Romana Gesslera. Gréckokatolícky farár Jozef Borovský s manželkou Evou aktívne pomáhali prenasledovaným lud’om pri prechode Karpatmi. Jozef bol v tom čase duchovným administrátorom fary v dedinke Latorka v Podkarpatskej Rusi, ktorá bola pred rokom 1939 súčastou Československa, ale po vzniku Slovenského štátu sa stala súčastou Mad’arska. Koncom roku 1941 
sa začalo masové vyvraždovanie Židov v údoliach smrti na Ukrajine. Mnohí z nich sa preto pokúsili o útek cez Karpaty do Madarska, ktoré bolo v tom čase pomerne bezpečné (The Righteous Among 2018; Wierzbieniec 2013, 338-353).

Zložité podmienky Židov pri prechode cez Karpaty viedli Borovského k rozhodnutiu, aby sa zapojil do poskytovania pomoci prenasledovaným. Správa o jeho dobrote a ochote sa rozšírila za Karpatmi na Ukrajine. Dozvedel sa o nej aj Gessler a v januári 1942 sa spolu s prvorodeným synom Elekom, ktorý mal vtedy 14 rokov, vydal na cestu. Opatrovatelke dvoch menších detí Elly zanechal kontakt na Borovského. Borovský mu poslal na pomoc dvoch mladíkov, ktorí sa vyznali v okolí, vedeli obíst’ nebezpečné miesta a s ich pomocou sa úspešne dostali na územie Podkarpatskej Rusi. Borovský ich prichýlil na fare, kde sa o nich starala jeho manželka Eva. Neskôr, ked' nastal vhodný okamžik, ich odprevadil do Mukačeva a postaral sa aj o dôvernú osobu, ktorá ich sprevádzala cestou vlakom až do Budapešti. V marci 1942 sa Elly rozhodla, že kvôli bezpečnosti detí bude lepšie, ked’ sa vyberú na cestu do Madarska. Informovala Borovského o svojom rozhodnutí a on k nej poslal dvoch mladíkov, aby ju spolu s detmi previedli v noci cez Karpaty. Po tažkej a dlho trvajúcej ceste sa napokon dostali na faru. Eva Borovská ich pri príchode vystríhala pred prítomnostou Nemcov v dome. Ked' nebezpečenstvo pominulo, strávili spolu niekolko dní. Potom ich Borovský odprevadil do Mukačeva, odkial’ odcestovali vlakom do Budapešti, kde sa rodina spolu zvítala. Po obsadení Mad’arska Nemcami Gesslerovci spolu s Elly utiekli do Rumunska a tam sa dožili oslobodenia (Gessler 2006, 30-33).

Mukačevský biskup Alexander Stojka zomrel v roku 1943 a jeho nástupcom sa stal v roku 1944 mladý 33-ročný intelektuálne založený kňaz Teodor Romža. Mukačevská eparchia mala v danom roku 257 farností s 460000 veriacimi a 354 kňazmi (Hranchak, 1995, 442-443). Biskup T. Romža bol predstavitelom novej generácie, ktorá vyrástla v demokratických podmienkach Československej republiky a zároveň bol absolventom prestížnej Gregoriánskej univerzity v Ríme. Výnimočný a v mnohých oblastiach odlišný od svojich predchodcov, ktorí ešte boli poznamenaní prostredím monarchie. Bol moderným človekom, ovládal viacero jazykov, venoval sa športu a rád jazdil na motocykli. V roku 1939 bol biskupom Stojkom menovaný za špirituála Kňazského seminára v Užhorode a zároveň tam pôsobil aj ako profesor filozofie. Po menovaní prijal 21. septembra 1944 biskupské svätenia v zložitých podmienkach blížiaceho sa frontu a čoskoro po príchode Červenej armády bol vystavený novým pomerom (Pop 2008, 216-217).

Spočiatku predstavitelia armády zachovali voči gréckokatolíckej cirkvi istú zdržanlivost’, ale už koncom roka 1944 pravoslávna cirkev s ich podporou preberala gréckokatolícke chrámy v oblasti Chustu. Pri príležitosti osláv velkej októbrovej revolúcie velenie 4. ukrajinského frontu zorganizovalo v Užhorode manifestáciu obyvatelstva za pripojenie k Sovietskemu zväzu. Slávnostné zhromaždenie sa konalo 6. novembra 1944 v Užhorode. Do Rákocziho kinosály bol pozvaný aj biskup T. Romža, na ktorého prítomnosti velenie armády trvalo. Bol vyzvaný, aby privítal armádu osloboditelku a jej velitela Jozefa Visarionoviča Stalina. Mal pod’akovat za oslobodenie a vyhlásit jednotu ruského, ukrajinského a zakarpatského ludu, vyzvat mládež ku vstupu do Červenej armády a v mene ludu poprosit', aby došlo k pripojeniu k Sovietskemu zväzu. Na zhromaždení biskup predniesol diplomatickú reč a vyhol sa výzve za pripojenie a akejkolvek politickej agitácii. Krajské noviny Zakarpatsk Ukrajina falošne informovala o príhovore biskupa T. Romžu, ktorý si želá pripojenie k Sovietskemu zväzu. Text prevzala aj kyjevská a moskovská tlač. Neskôr po prijatí „Manifestu“ na zjazde národných výborov konanom 26. novembra 1944 v Mukačeve bol biskup T. Romža spolu s kúriou vyzvaný aby „Manifest“ podpísal, čo on aj jeho spolupracovníci odmietli. Zhoršujúce sa postavenie gréckokatolíckej cirkvi umocňovalo násilné preberanie chrámov a farností zo strany Pravoslávnej cirkvi za asistencie Červenej armády. Došlo aj k zatýkaniu kňazov, čo napokon biskupa prinútilo začiatkom januára $\mathrm{k}$ jednaniu s Ludovou radou na čele s predsedom Ivanom Turianicom. Počas jednania jasne demonštroval svoj apolitický postoj a vôlu 
spolupracovat's Ludovou radou na poli kultúry a v sociálnych otázkach. Navrhol zorganizovanie zbierky v eparchii na pomoc sirotám a vdovám po vojakoch, ktorí zahynuli pri oslobodzovaní Podkarpatskej Rusi. Zo strany L’udovej rady však voči biskupovi a gréckokatolíckej cirkvi pretrvávalo nepriatel'ské stanovisko, a to napriek istej spolupráci, ktorá v nasledujúcom období prebehla (Puskás 2011, 127-130; Pekar 1967, 159-164).

Negatívne stanoviská sovietskeho vedenia viedli biskupa $\mathrm{T}$. Romžu k zintenzívneniu činnosti $\mathrm{v}$ prospech veriacich. Hojne navštevoval jednotlivé farnosti a povzbudzoval k vernosti gréckokatolíckej cirkvi. Zároveň pripravoval kňazov na obdobie velkej skúšky. Po podpísaní zmluvy medzi Československom a Sovietskym zväzom o odstúpení Podkarpatskej Rusi - Zakarpatskej Ukrajiny Sovietskemu zväzu v júni 1945 sa stupňovala diskreditačná kampaň proti gréckokatolíkom. Došlo k zatýkaniu a súdnym procesom s vybranými duchovnými. Za danej situácie sa najprv v Užhorode na sviatok Premenenia Pána a potom 28. augusta 1945 na sviatok Nanebovzatia Panny Márie v Mukačeve na Černečej hore uskutočnili tradičné púte za účasti desattisíc veriacich, ktorí prichádzali v procesiách, a tak verejne demonštrovali svoju vernost’ gréckokatolíckej cirkvi. Počas týchto pútí sa biskupovi naskytla jedinečná možnost’ ovplyvňovat' postoje duchovných a veriacich, ktorých napriek hroziacemu nebezpečenstvu povzbudzoval k zachovaniu vernosti (Puskás 2011, 150-152).

Tragédiu gréckokatolíckej cirkvi predznamenal vývoj na západnej Ukrajine, kde bola dňa 10. marca 1946 v Lvove počas zinscenovaného soboru zrušená Brest-Litovská únia. Nasledovali ich gréckokatolíci z Rumunska (Sedmohradsko), kde bola podobným spôsobom zrušená únia gréckokatolíkov v Bukurešti 1. decembra 1948. Tlak na biskupa T. Romžu vzrástol, ale kedže bol neoblomný, požiadal prvý tajomník Komunistickej strany Ukrajiny Nikita Sergejevič Chruščov, ktorý chcel zlikvidovat teroristov v Zakarpatskej oblasti, J. V. Stalina o súhlas k fyzickej likvidácii biskupa T. Romžu a vyslaniu špeciálneho komanda z Moskvy. Dňa 26. októbra 1947 sa komando 4. výzvedno-diverzného oddielu pokúsilo biskupa Romžu zavraždit na ceste do Užhorodu, ale po neúspešnej akcii ho napokon zavraždili 1. novembra 1947 smrtiacou injekciou v nemocnici. Po smrti biskupa bola štruktúra gréckokatolíckej cirkvi rozbitá a kňazi, ktorí odmietali prestup do pravoslávnej cirkvi boli uväznení a deportovaní. K formálnemu zániku gréckokatolíckej cirkvi na Zakarpatskej Ukrajine došlo 28. augusta 1949, ked’ bola zrušená Užhorodská únia (Halagida 2013, 121-122; Borza 2003, 23; Pop 2008, 218; Pekar 1967, 164-169).

\section{REFERENCES}

Babjak, Ján. 2009. Zostali verní. Osudy gréckokatolíckych kňazov. Zväzok I. Prešov.

Borza, Peter. 2003. Blahoslavený Vasil' Hopko, prešovský pomocný biskup (1904 - 1976). Prešov.

Borza, Peter. 2013. Cyrilo-metodská tradícia medzi gréckokatolíkmi na Slovensku v 20. storočí.

In Junek, Marek (ed.). Cyrilometodějská tradice v 19. a 20. století, období rozkvětu i snah o umlčení. Praha, 165-179.

Borza, Peter. 2014. Formy pomoci Židom zo strany Gréckokatolíckej cirkvi na Slovensku v rokoch 1939 - 1945. In Historia Ecclesiastica : časopis pre dejiny cirkví a náboženstiev v Strednej Európe. 5/2, 112-128.

Fenich, Vladimir. 2015. Долаючи етнічні стереотипи та національні мифи: Греко- католицька церква в пидкарпатській историографіï 1890 - 1945 [Overcoming ethnic stereotypes and national myths: The Greek Catholic Church in Subcarpathian historiography from 1890 to 1945]. In Fenich, Vladimir - Snicer, Igor (eds.) Пидкарпатська Русь в року Другої свитової вийни [Subcarpathian Rus in years of the WW II.]. Užhorod, 102-125. 
Gessler, A. Roman, 2006. A Life's Journey: From Shattered Dreams to Serendipity. A Memoir. Tel Aviv.

Halagida, Igor. 2013. Między Moskwą, Warszawą i Watykanem. Dzieje Kościoła greckokatolickiego w Polsce w latach 1944 - 1970. Warszawa.

Hranchak, Ivan et al. 1995. Нариси історії Закарпаття, Том II., (1918 - 1945) [Essays on the history of Transcarpathia, Part II., (1918 - 1945)]. Užhorod.

Katolícke Slovensko 833 - 1933. 1933.Trnava.

Magocsi, Paul Robert. 1994. Формування національної самосвідомості Пидкарпатська 1848 1948 [Formation of national consciousness Subcarpathian]. Užhorod 1994.

Pekar, Atanas. 1967. Нариси історії церкви Закарпаття [Essays on the history of church in the Transcarpathia]. Rome.

Pekar, Atanas. 2000. Греко-католицка церква в кордонах Чехословаччини 1919 - 1939 [Greek Catholic Church at the borders of Czechoslovakia 1919-1939]. In Mušinka, Mikuláš. (ed.). Zakarpatská Ukrajina v rámci Československa (1919 - 1939). Prešov.

Pop, Ivan. 2008. Podkarpatská Rus. Osobnosti jeji histórie, vědy a kultury. Praha.

Puskás, László. 2011. Blažený Teodor Romža. Život a smrt’ biskupa - mučeníka. Michalovce.

Schematismus cleri Graeci Ritus Catholicorum Dioecesis Mukacensis ad Annum Domini 1938. 1939.

Užhorod.

Statistický lexikón obcí v Republice Československé IV. Země Podkarpatoruská. 1937. Praha.

Švorc, Peter. 2006. Zakliata krajina. Podkarpatská Rus 1918 - 1946. Prešov.

The Righteous Among 2018. The Righteous Among The Nations, Borovský FAMILY. http:// db.yadvashem.org/righteous/family.html?language =en\&itemId=6966918.

Vasil, Cyril. 2000. Gréckokatolíci, Dejiny - osudy - osobnosti. Košice.

Wierzbieniec, Waclaw. 2013. Żidowska gmina wyznaniowa w Jarosławiu w okresie II Rzeczypospolitej i jej losy podczas holocaustu. In Kónya, Peter ed. Židia pred a za Karpatmi v priebehu stáročí. Prešov, 338-353.

Zákon č. 96/1925 Sb. z. Zákon č. 96/1925 Sb. z. a n. o vzájemných poměrech náboženských vyznání.

Zákon kongruovýč. 122/1926 Sb. z. Zákon kongruový č. 122/1926 Sb. z. a n. zákon ze dne 25. června 1926 o úpravě platů duchovenstva církví a náboženských společností státem uznaných, prríp. recipovaných.

SUMMARY: GREEK CATHOLIC CHURCH IN CARPATHIAN RUTHENIA AND CLASH OF CULTURES IN 1945. The Greek Catholic Church in Carpathian Ruthenia, in comparison with the rest of Czechoslovakia, where it was a minority, held an important position in society. For centuries, it has played an important role in raising the educational and cultural level of the local population. A complex of educational and educational institutions, not only in Uzhgorod, but also Chust and individual parishes, served for this purpose. This activity was complemented by associations and religious organizations. In the retrospective view of the period between 1920 and 1945, we can conclude that there has been ongoing progress in this area of activity. However, with the arrival of the Red Army in 1944 and the annexation of Carpathian Ruthenia, the entire system was destroyed and, finally, the Greek Catholic Church itself.

The significant influence of the Greek Catholic clergy and intelligence on the events in the society of Subcarpathian Rus manifested itself mainly through the actions of the individual bishops. Each of them was an interesting personality. Bishop Anton Pap left the eparchy after the break-up of the Mukachevo monarchy and lived in Hungary. His place was taken by Bishop Peter Gebej, who found his way to the representatives of the political 
and religious environment of the Czechoslovak Republic. Through his attitudes, there has been a positive collaboration between the state and the church, which ultimately helped to eliminate the injustices caused by the Orthodox movement and the consolidation of the situation in the Greek-Catholic Church. His successor, Alexander Stojka, continued in the established line, but after the annexation of Carpathian Ruthenia by Hungary in 1939, he experienced the support of Hungarian political circles, which, however, did not last long in the face of his national demands for the benefit of the local population. As a result, he focused his attention on the apostolate and on pastoral as well as social action for the good of his believers.

The specificity of the war period was to help the racially persecuted Jews who escaped from persecution with occupied Poland to Hungary, which also included Carpathian Ruthenia. The grant of selfless help can be seen in the example of priest Jozef Borovský and his wife Eva. This area of activity of Greek Catholics is still awaiting detailed research and clarification.

After the death of Bishop A. Stojka in 1943, the Holy See appointed a young intellectual priest, Teodor Romžu, to replace his generation. Bishop Romza grew up in an environment of democratic Czechoslovakia, and his attitudes were clearly visible. In the difficult conditions of crossing the front and changing the state, he tried to defend the interests of the Greek Catholic Church to such an extent that top Soviet officials had him brutally murdered in 1947. The Greek Catholic Church was abolished and believers forced to enter the Orthodox Church. However, Saint Cyril and Methodius' rich spiritual and cultural heritage remained hidden and the Greek Catholic Church was reborn in 1989.

Doc. ThDr. Peter Borza, PhD.

Department of History

Faculty of Arts

Pavol Jozef Šafárik University in Košice

Moyzesova 9

04001 Košice

Slovakia

peter.borza@upjs.sk 